\title{
Physical exercise intensity prescription to improve health and fitness in overweight and obese subjects: A review of the literature
}

\author{
Gian Pietro Emerenziani ${ }^{1}$, Silvia Migliaccio ${ }^{1}$, Maria Chiara Gallotta ${ }^{1}$, Andrea Lenzi ${ }^{2}$, \\ Carlo Baldari $^{1 \#}$, Laura Guidetti ${ }^{1}$ \\ ${ }^{1}$ Department of Movement, Human, and Health Sciences, University of Rome "Foro Italico", Rome, Italy; \\ \#Corresponding Author: carlo.baldari@uniroma4.it \\ ${ }^{2}$ Department of Experimental Medicine, University of Rome "La Sapienza”, Rome, Italy
}

Received 17 April 2013; revised 18 May 2013; accepted 6 June 2013

Copyright (C) 2013 Gian Pietro Emerenziani et al. This is an open access article distributed under the Creative Commons Attribution License, which permits unrestricted use, distribution, and reproduction in any medium, provided the original work is properly cited.

\begin{abstract}
Obesity is one of the greatest public health challenges of the 21st century. Overweight and obesity drastically increase a person's risk of developing chronic non-communicable diseases (NCDs), including cardiovascular disease, cancer and diabetes. Furthermore, obesity is already responsible for $2 \%-8 \%$ of health costs and $10 \%-13 \%$ of deaths in several industrialized countries. Lifestyle modifications involving changes in exercise, diet and psychological support are effective in reducing the incidence of overweight. Moreover, positive effects of physical activity (PA) for weight loss and prevention of weight regain are well documented. It was recognized that health benefits regarding both psychological and physiological aspects, such as improving cardiorespiratory and muscular fitness and/or decreasing depression symptoms, can be obtained from numerous activities. Public health institutions (American College of Sports Medicine, World Health Organization) provide recommendations for PA (volume, frequency, intensity and type of exercise) to achieve positive effects, at all ages and for many diseases and disorders situations. Although exercise under guidelines can be safely performed by obese subjects, several questions still need to be fully answered. In facts, the exercise program should be tailored according to an individual's habitual physical activity, physical function, health status, exercise responses, and stated goals. Thus, this review analyzes the

*Gian Pietro Emerenziani is supported by a fellowship funded by PRIN (year 2009-2009KENS9K_004).
\end{abstract}

intensity of PA parameters. In the last years, research has been focused on the individualization of the right intensity in which different types of subjects' condition must undergo to achieve the health goals. Aerobic exercise has been commonly used to reach weight loss goal. Prescription of aerobic exercise in clinical practice is frequently based on the percentage of maximum heart rate $\left(\% \mathrm{HR}_{\max }\right)$, heart rate reserve

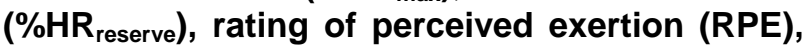
maximal oxygen consumption $\left(\% \mathrm{VO}_{2 \max }\right)$ and for unhealthy subjects, peak oxygen consumption $\left(\% \mathrm{VO}_{2 \text { peak }}\right)$. It has been shown that unhealthy subjects, such as individuals affected by diabetes, obesity and cardiovascular diseases have a reduced maximal aerobic exercise capacity. For instance, using the formula based on percentage of $\mathrm{HR}_{\max }$ or $\mathrm{VO}_{2 \max }$, it could be prescribed heavy exercises, which would result not appropriated and fully functional for the specific individual goal. To avoid this problem, another approach to individualize aerobic exercise could be to consider the gas exchange parameters such us aerobic gas exchange threshold (AerT $T_{G E}$ ). AerT $T_{G E}$ corresponds to the first increase in blood lactate during incremental exercise. This review offers an overview of the different methods to assess exercise intensity, considering the different subjects health characteristics, in order to choose the right methods to achieve the health goals in obese and overweight subjects.

Keywords: Obesity; Overweight; Exercise Intensity Prescription; Gas Exchange Thresholds; Health 


\section{INTRODUCTION}

In the last century, chronic diseases, also known as non-communicable diseases (NCDs), have become the most serious public health problem in terms of morbidity, mortality and economic costs [1]. NCDs are diseases of long duration and generally slow progression. Cancer, cardiovascular diseases (CVD), chronic respiratory diseases and diabetes are by far leading causes of mortality, representing $63 \%$ of all deaths [1]. Overweight and obesity conditions are recognized risk factors for premature mortality and chronic health conditions such as type 2 diabetes, coronary heart diseases and hypertension. According to the World Health Organization, at least 2.8 million adults die each year as a result of being overweight or obese. In addition, $44 \%$ of the diabetes burden, $23 \%$ of the ischemic heart disease burden and between $7 \%$ and $41 \%$ of certain cancers are attributable to overweight and obesity. The prevalence of overweight and obesity has increased to epidemic proportions in the industrialized world and is now dramatically on the rise in low- and middle-income countries, particularly in urban settings [2]. Overweight and obesity are commonly defined as abnormal or excessive fat accumulation that presents a risk to health. These conditions are usually assessed in clinical setting using the body mass index (BMI), a person's weight (in kilograms) divided by the square of his or her height (in metres) $(\mathrm{BMI}=$ weight $[\mathrm{kg}]$ $\times$ height $\left[\mathrm{m}^{-2}\right]$ ). A person with a BMI between 25 and 29.9 is considered overweight, while a person with a $\mathrm{BMI}$ over 30 higher is generally considered obese. However, criticisms for the use of the BMI for a correct characterization of body composition assessment are increasing due to inaccurate evaluation of either fat or muscle mass in some individuals such as resistance athletes or sarcopenic subjects.

Regular physical activity (PA) provides a multitude of health benefits and it is considered an essential component of primary and secondary prevention for most of the NCDs $[3,4]$. Studies showed that subjects who increased their level of PA over time have a decreased risk of mortality compared to those who were consistently unfit [5-7]. Despite these positive effects, physical inactivity remains an international health problem and its negative effects on health were well documented [8] as well as the negative economic consequences $[9,10]$. Although charges associated with these risk factors were highest for the oldest subjects (aged 65 years and older) and for individuals with chronic conditions, nearly half of aggregate charges were generated from the group aged 40 to 64 years without chronic diseases [9].

Due to the well known positive effects of PA on health, several public organizations, such as American College of Sports Medicine, World Health Organization, Center for Disease Control and Prevention (CDC), the American
Heart Association (AHA), have established PA guidelines. In May 2004, the 57th World Health Assembly (WHA) endorsed the World Health Organization (WHO) Global Strategy on Diet, Physical Activity and Health [11].

The overall goal of the Global Strategy on Diet, Physical Activity and Health is to promote and protect health by facilitating the development of an environment allowing to act at individual, community, national and global levels, which, when taken together, will lead to a decrease in morbidity and mortality rates related to unhealthy diet and PA [11]. The PA recommendations for weight loss and prevention of weight gain included in these guidelines are detailed such that individuals have the possibility to choose different exercise intensities, durations, frequencies, or combinations of those. This review focuses on the different methods to assess the exercise intensity in overweight and obese subjects. This paper could be useful for professional figures working to achieve and maintain fitness: physicians, health practitioners, kinesiologists, and exercise physiologists to update the knowledge of the different approaches for prescribing exercise intensity for obese and overweight subjects.

\subsection{Defining Physical Activity and Physical Fitness}

PA is defined as any bodily movement produced by skeletal muscles that require a significant increase of energy expenditure as compared to a resting phase [12]. We can consider leisure-time, exercise, sport, occupational work and transportation as all forms of PA. Exercise is a type of PA that is usually performed repeatedly over an extended period of time with the aim to improve fitness, physical performance or health. On the other end, Physical Fitness (PF) is defined by WHO as the ability to perform muscular work satisfactorily. Health-related fitness components are morphological, cardiorespiratory, muscular, motor and metabolic components. Commonly $\mathrm{PF}$ refers to aerobic endurance capacity as measured by maximal oxygen uptake $\left(\mathrm{VO}_{2 \max }\right)$ or peak oxygen uptake $\left(\mathrm{VO}_{2 \text { peak }}\right) . \mathrm{VO}_{2 \max / \text { peak }}$ is strongly associated with physical efficiency and health. Studies have demonstrated that high level of endurance capacity results in a decrease of CVD [13,14]. In fact, longitudinal studies show that higher levels of cardiorespiratory fitness $\left(\mathrm{VO}_{2 \max }\right)$ are associated with a lower mortality rate [15].

\subsection{Overweight and Obese Cardiorespiratory Training Research}

Cardiorespiratory fitness depends on the integration of the cardiac and pulmonary systems, and it is defined as the ability of the body to transport and use oxygen. The fitness professionals should be aware that overweight and obese subjects should be poorly conditioned since 
the aerobic capacity of these subjects has been shown to be low, and in some instances, critically low [16-20]. De Souza et al. [21] reported that aerobic capacity of severe obese subjects $(44 \leq \mathrm{BMI} \leq 54.8)$ ranging from 16.1 to $34.7 \mathrm{ml} \cdot \mathrm{min}^{-1} \cdot \mathrm{kg}^{-1}$. Furthermore, Belli et al. [22] indicated that obese subjects affected by type 2 diabetes have a low aerobic capacity $\left(\mathrm{VO}_{2 \max }=22 \mathrm{ml} \cdot \mathrm{min}^{-1} \cdot \mathrm{kg}^{-1}\right)$. The poor aerobic capacity should be taken into consideration when determining exercise intensity in deconditioned subjects. Several recent published results showed that a moderate aerobic exercise program could improve cardiorespiratory condition in obese subjects [16,21-29]. For instance, Millen et al. [30] showed that peak oxygen consumption increased from $27.0 \pm 5.1$ to $28.8 \pm 5.8$ $\mathrm{ml} \cdot \mathrm{min}^{-1} \cdot \mathrm{kg}^{-1}$ in overweight and obese subjects upon a 6 week of aerobic exercise training ( $\geq 3$ days/week). The correlation between obesity and CVD is due to the potential presence of several risk factors in obese individuals such as hypertension, type 2 diabetes, and dyslipidemia [31]. Interestingly, it is important to make clear that the health benefits of weight reduction can be obtained with PA even without the achievement of individual optimal body weight. In fact, already two decades ago, some studies demonstrated that reductions of $5 \%$ to $10 \%$ in body weight could be already associated with health benefits for the improvement of risk factors, such as decreased blood pressure $[32,33]$. Among the parameters to be considered in the exercise program for unhealthy population, intensity has received special attention.

\subsection{Importance of Physical Activity in Treatment of Obesity}

Early data of the literature suggested that the PA associated to caloric restriction resulted in the best treatment of obesity [34-37]. The studies showed that when the prescribed exercise program resulted in a significant negative energy balance, a more substantial weight loss was obtained [37-39]. Additionally, Ross et al. [38] showed that weight loss is positively associated with the volume of performed PA. The effects of exercise are maintained even when the exercise ends. In fact, the excess post exercise oxygen consumption results in a prolonged post exercise increase in caloric consumption. Moreover, fat-free mass is better maintained in individuals who performed weight training as part of their exercise program [40] and, therefore, exercise prescription should include aerobic and muscular fitness training. Exercise length is usually extended to increase caloric consumption and, upon that duration, is inversely correlated with the intensity and, thus, aerobic exercise (moderate intensity) is preferred to anaerobic exercise (high intensity). Lafortuna et al. [41] showed that although low and high intensity exercise groups obtain equal body weight loss, the higher intensity exercise program showed a better generalized improvement in muscle performance and physical fitness. Moreover, it has been shown that exercising in multiple bouts throughout the day can be as effective for weight loss as exercising for a single longer continuous bout $[42,43]$. Thus, the fitness professionals should individualize the intensity and the type of exercise upon the goals and overall health of the subjects.

The public health organizations guidelines indicate a moderate intensity exercise (aerobic) for overweight and obese subjects to be performed most of the day of the week $[11,42]$. More recent studies have drawn attention to the effects of moderate and vigorous intermittent exercise on weight loss $[44,45]$.

ACSM Position Stand [34] emphasizes the importance to perform moderate intensity PA, between 150 and 250 $\min \cdot \mathrm{wk}^{-1}$, to significantly prevent weight gain. On the other hand, this moderate PA provides only modest weight loss, while greater amounts of PA $\left(\geq 250 \mathrm{~min} \cdot \mathrm{wk}^{-1}\right)$ have been associated with clinically significant weight loss. Further, moderate intensity PA (between 150 and $250 \mathrm{~min} \cdot \mathrm{wk}^{-1}$ ) has been shown to improve weight loss when associated to moderate caloric restriction but not severe caloric restriction.

Cross-sectional and prospective studies indicate that after appropriate weight loss, weight maintenance is improved by a regular PA $\geq 250 \mathrm{~min} \cdot \mathrm{wk}^{-1}$. World Health Organization [11] recommends to perform PA which would include leisure time PA to improve cardiorespiratory and muscular fitness, bone health and reduce the risk of NCDs and depression. Additionally, WHO suggests for adults, aged 18 - 64, to perform at least 150 minutes of moderate-intensity aerobic PA throughout the week or to perform at least 75 minutes of vigorous-intensity aerobic PA throughout the week or an equivalent combination of moderate and vigorous intensity activity. Generally, the exercise intensity suggested by public health recommendations is moderate. Fitness professionals should be aware about the terms "moderate" and "vigorous" when they are working with overweight and obese individuals. In fact, these subjects have low cardiorespiratory fitness, which is expressed by reduced oxygen uptake $\left(\mathrm{VO}_{2}\right)$, decreased daily activity and low exercise tolerance.

\section{EXERCISE INTENSITY PRESCRIPTION}

Recently, the problem to identify the exercise intensity for overweight and obese subjects has become more acute. Intensity component could be described in both absolute and relative terms. Relative intensity takes into consideration the exercise capacity of the subjects to perform the activity, while absolute intensity only considers the demands of the activity. The positive effects of 
PA could be reached performing exercise with low intensity (aerobic metabolism) and long duration or exercise with high intensity (anaerobic metabolism) and short duration.

Exercise intensity for overweight and obese subjects could be evaluated in different manner [46,47]. Commonly, exercise intensity is based on a measured, or estimated, maximal/peak oxygen uptake $\left(\mathrm{VO}_{2 \max / \text { peak }}\right)$ or maximum heart rate $\left(\% \mathrm{HR}_{\max }\right)[42,43,48]$. At present, American College of Sports Medicine suggests to use three variables as a manner to monitor the intensity: $\mathrm{VO}_{2 \max }$, HR and rate of perceived exertion (RPE). Moreover during the last years gas exchange parameters, such as aerobic gas exchange threshold $\left(\right.$ Aer $\left._{\mathrm{GE}}\right)$, have been used more frequently. All these parameters could be used alone, or in combination, to monitor exercise intensity $[16,21-29,49]$. Parameters based on $\% \mathrm{VO}_{2 \max }$ or $\% \mathrm{HR}_{\max }$ should be used with prudence to prescribe exercise, due to the lower cardiorespiratory fitness of overweight and obese subjects [50].

It is well known that exercising at a given absolute terms can elicit specific physiological responses for different individuals [48]. In fact, no adjustment is usually made for each person's exercise capacity. Moreover, the use of relative terms, such as $\% \mathrm{VO}_{2 \max }$ has been substantially criticized [51,52], since it seems that the relative parameters alone without considering the aerobic gas exchange threshold $\left(\right.$ Aer $\left._{\mathrm{GE}}\right)$ is not sufficient.

For these reasons, during the last years, aerobic gas exchange threshold $\left(\right.$ Aer $\left._{\mathrm{GE}}\right)$ has become more frequent to prescribe exercise intensity in un-healthy population $[16,22,53-60]$. The aerobic gas exchange threshold could be a valid tool to delineate the "training zone" for endurance training [60] and for un-healthy subjects [22].

In the next paragraphs, the difference between these parameters is discussed. As previously reported by Meyer et al. [60], in order to make clear the matter, we use different terms: aerobic gas exchange thresholds Aer $_{\mathrm{GE}}$ to identify the points sometimes called "ventilatory threshold", "ventilatory threshold 1", anaerobic threshold [61]; and anaerobic gas exchange threshold $\mathrm{AnaT}_{\mathrm{GE}}$ to identify the point also called "respiratory compensation point" or "ventilatory threshold 2".

\subsection{Exercise Prescription Using Oxygen Uptake data}

Percentage of maximal oxygen uptake $\left(\% \mathrm{VO}_{2 \max }\right)$, peak oxygen uptake $\left(\% \mathrm{VO}_{2 \text { peak }}\right)$ or oxygen uptake reserve $\left(\mathrm{VO}_{2 \mathrm{R}}\right)$ could be used as exercise intensity prescription $[34,42,62] . \mathrm{VO}_{2 \mathrm{R}}$ is the difference between $\mathrm{VO}_{2 \max }$ and resting $\mathrm{VO}_{2}$. When we use these variables to assess exercise intensity we should be aware that the relationship between the exercise intensity determined by the $\% \mathrm{VO}_{2 \mathrm{R}}$ and the $\% \mathrm{VO}_{2 \text { peak }}$ mean regression seems to be influenced by the degree of obesity [48].

\subsection{Exercise Prescription Using Metabolic Equivalents}

The energy expenditure during PA depends on the intensity, type and duration of activity. The method to assess the energy expenditure used worldwide is the metabolic equivalent unit (MET), which is defined as the ratio of work metabolic rate to a standard resting metabolic rate of $1.0 \mathrm{cal} \cdot \mathrm{kg}^{-1} \cdot \mathrm{h}^{-1} .1 \mathrm{MET}$ is the resting metabolic rate obtained during rest and is equivalent to an oxygen uptake $\left(\mathrm{O}_{2}\right)$ of $3.5 \mathrm{ml} \cdot \mathrm{kg}^{-1} \cdot \mathrm{min}^{-1}$. Compendium of Physical Activities has been developed to facilitate comparison of coded PA intensity levels across observational studies $[63,64]$. Activity are listed in the Compendium as multiples of the resting MET level and range from 0.9 (sleeping) to 18 METs (running at $17.5 \mathrm{~km} \cdot \mathrm{h}^{-1}$ ). According to the compendium, exercise intensity is classified as lightintensity (1.6 - 2.9 METs), moderate-intensity (3 - 5.9 METs), and vigorous-intensity ( $\geq 6$ METs) activities $[63,64]$. Considering that overweight and obese subjects have low cardiorespiratory fitness, individual exercise effort is not correlated with the MET value. For instance, De Souza showed that maximal exercise capacity of obese subjects ranging from 4.6 and 10 METs. Therefore, using 3 - 5.9 METs to prescribe moderate exercise intensity is not appropriated for this population.

\subsection{Exercise Prescription Using Heart Rate}

Percentage of maximum heart rate $\left(\% \mathrm{HR}_{\max }\right)$, or heart rate reserve (HRR) could be used as a manner to monitor exercise intensity. While we are using HR data to monitor exercise intensity we must consider that:

- The linear relationship between $\mathrm{HR}$ and $\mathrm{VO}_{2}$ depends on the mode of exercise.

- The equations to estimate maximal HR $[65,66]$ have large standard deviations. Using these formulas, we could underestimate or overestimate the true level of physical stress imposed during exercise.

- HR could be influenced by a lot of physiological parameters, climate and environment conditions [67, $68]$.

Therefore, caution should be taken when using equations to estimate maximal HR $[65,66]$ and when we use HR in order to prescribe exercise intensity.

\subsection{Exercise Prescription Using Rate of Perceived Exertion}

Perceived exertion is how hard subjects feel their body is working and it is based on general fatigue. Previous studies have demonstrated that an increase in physio- 
logical parameters such as $\mathrm{HR}$ and $\mathrm{VO}_{2}$, are associated with more intense perceptions of exertion [69]. The scale is valid in that it generally evidences a linear relation with both heart rate and oxygen uptake during exercise [70,71]. The use of RPE could be important in two situations: if the heart-rate measurement is for any reason difficult or if the individual is on medication(s) which could alter normal heart rate response to physical stress. When fitness trainer uses this scale to assess exercise intensity it should be consider that:

- perceived exertion is a method to determine the intensity of effort, strain, and/or discomfort felt during exercise;

- the range of sensations must correspond to the scale;

- either the RPE should be made specific to the overall body perception or the perception derived from a certain anatomical region of the body such as chest, arms and/or legs;

- careful explanation of the scale is necessary before using so that individual is able to understand the meaning of the descriptors.

\subsection{Exercise Prescription Using Gas Exchange Parameter}

Submaximal parameters such as lactate or gas exchange thresholds are better markers of the relative stress induced by exercise $[53,60]$. However, the use of the two submaximal gas exchange thresholds (aerobic, AerT $\mathrm{TE}_{\mathrm{GE}}$ and anaerobic, $\mathrm{AnT}_{\mathrm{GE}}$ ) for exercise intensity prescription, have loss attention although their noninvasive nature make them an attractive tool [60]. Gas exchange thresholds allow to prescribe the exercise intensity based on the real subject's capacity to perform physical exercise. Considering that obese population has low cardiorespiratory fitness, it can be very important to use thresholds concept when exercise intensity has to be chosen. For overweight and obese subjects, the use of lactate parameters requires the continuously monitoring of plasma lactate levels that is not an easy practice to use for this population. On the contrary, gas exchanges parameters require only gas exchange analysis and it could be easier to apply for intensity exercise prescription. For all these reasons, we focused on gas exchange parameters and not on lactate thresholds. These methods to assess exercise intensity have been already used for subjects affected by various chronic diseases associated with abnormally low peak oxygen uptake $\left(\% \mathrm{VO}_{2 \text { peak }}\right)$ such as subjects with chronic heart failure [72,73] and obesity [59].

Aerobic Gas Exchange Threshold (AerT $\left.T_{G E}\right)$.

The aerobic threshold marks the upper limit of an almost exclusively aerobic metabolism that permits exercise lasting for hours at a lactate level of approximately 2 $\mathrm{mmol} \cdot \mathrm{l}^{-1}[74]$. This point is associated with optimal ventilatory efficiency $[75,76]$. The $\operatorname{AerT}_{\mathrm{GE}}$ corresponds to the anaerobic threshold described by Wasserman et al. [61].

The AerT $\mathrm{T}_{\mathrm{GE}}$ is defined as the maximum exercise intensity fully supported by aerobic metabolism, representing in general a mild to moderate exercise intensity [77,78]. This landmark occurs at the time of the first rise in blood lactate concentration that leads to an increase of carbon dioxide output $\left(\mathrm{CO}_{2}\right)$ and a non linear increase of ventilation $\left(\mathrm{V}_{\mathrm{E}}\right)$ occurs as a results.

Generally there are different procedures to determine the AerT $_{\mathrm{GE}}$ :

- V-slope method [79]: this method is based on the relationship between $\mathrm{VO}_{2}$ and $\mathrm{VCO}_{2}$. Before the ventilatory threshold is reached, $\mathrm{VO}_{2}$ and $\mathrm{VCO}_{2}$ tend to rise at roughly the same rate and a best-fit line through these points will have a slope close to 1 . Once the ventilatory threshold is reached and a metabolic acidosis develops, $\mathrm{VCO}_{2}$ rises at a faster rate than $\mathrm{VO}_{2}$ and a best fit line through the points will now have a slope greater than 1 . The point at which the two best-fit lines intersect is the AerT $\mathrm{T}_{\mathrm{GE}}$.

- The first rise in the ventilatory equivalent for $\mathrm{O}_{2}$ $\left(\mathrm{VE} / \mathrm{VO}_{2}\right)$ without a concomitant rise in the ventilatory equivalent for $\mathrm{CO}_{2}\left(\mathrm{VE} / \mathrm{VCO}_{2}\right)[60]$.

- Plotting the ventilatory equivalent $\left(\mathrm{VE} / \mathrm{VO}_{2}\right)$ as a function of $\mathrm{VO}_{2}$ in order to identify the point during exercise where this curve has its minimum value $[75,76,80,81]$.

- The first overproportional increase in the respiratory exchange ratio $\mathrm{RER}=\mathrm{VCO}_{2} / \mathrm{VO}_{2}$.

- The first increase in the expiratory fraction of $\mathrm{O}_{2}$.

- The first upward bending changes in the VE versus HR slope during incremental exercise [82].

Anaerobic Gas Exchange Threshold ( $A n T_{G E}$ ).

The $\mathrm{AnT}_{\mathrm{GE}}$ represents the maximal workload where production and elimination of lactate are in equilibrium [83]. Thus, at intensities above the individual anaerobic threshold, there is a net and continued accumulation of lactate in muscle and in blood $[80,83]$. At this point, an overproportional increase of $\mathrm{VE}$ as related to $\mathrm{VCO}_{2}$ occurs.

Generally $\mathrm{AnT}_{\mathrm{GE}}$ is determinate:

- By plotting $\mathrm{VE}$ (y-axis) versus $\mathrm{VCO}_{2}$ (x-axis). Two regression lines are fitted for the upper and lower part of the relation and their intersection represents the $\mathrm{AnT}_{\mathrm{GE}}$. Moreover, the first systematic increase in $\mathrm{VE} / \mathrm{VCO}_{2}$ parameter or the first decrease in the expiratory fraction of $\mathrm{CO}_{2}$ could be used as alternative indicators.

- By the heart rate variability threshold during graded exercise [84]. The reliability of this method has not been assessed for overweight and obese population.

- From the second upward bending of the graph representing $\mathrm{VE}$ (y-axis) versus $\mathrm{VO}_{2}$ (x-axis) [85]. 


\section{CONCLUSIONS}

Physical inactivity, a condition which is commonly seen in overweight and obese individuals, is usually associated with low cardiopulmonary and functional capacities. Recent data demonstrated that both the prevalence of excess of body weight and low cardiorespiratory capacity drastically increase a subject's risk of developing a number of NCDs [62]. Since obesity results from a chronic energy imbalance whereby intake exceeds expenditure, PA plays a pivotal role on body weight management. Public health organizations suggest to perform moderate intensity exercise (aerobic) most, preferably all, days of the week. Since overweight and obese subjects have a low cardiorespiratory capacity and low exercise tolerance, the prescription of the intensity of exercise should be based on the real individual capacity to perform physical exercise. Exercise intensity can be prescribed based upon maximal oxygen uptake $\left(\% \mathrm{VO}_{2 \max }\right)$, maximum heart rate $\left(\% \mathrm{HR}_{\max }\right)$, rate of perceived exertion (RPE). These parameters could be influenced by many physiological and environmental conditions, such as the degree of obesity, psychological aspects, pharmacological therapy. Furthermore, studies showed that the use of these parameters alone, without considering the aerobic gas exchange threshold $\left(\right.$ Aer $\left._{\mathrm{GE}}\right)$, is not sufficient. Moreover, although valid, the mentioned methods do not guarantee that the intensity of exercise coincides with that based on AerT $\mathrm{T}_{\mathrm{GE}}$, which ensures a fully aerobic intensity and can guarantee that the exercise is performed accordingly to the capacity of each subject. Therefore, Aer $_{\mathrm{GE}}$ could be a valid alternative and more appropriate method to prescribe exercise intensity. The AerT $\mathrm{T}_{\mathrm{GE}}$ is defined as the maximum exercise intensity fully supported by aerobic metabolism, representing in general a mild to moderate exercise intensity. Additionally, since the AerT $_{\mathrm{GE}}$ is a direct and objective measure of cardiopulmonary capacity, the intensity of the exercise is determined individually according to physical subject's capacity.

In conclusion, there are different manners to evaluate the Aer $\mathrm{T}_{\mathrm{GE}}$. Although V-slope is a standard gold method, other less expensive methods have been developed. All the parameters used to assess the right exercise intensity for obese and overweight subjects could be used alone or in combination. Considering the benefits to use gas exchange parameters to evaluate the subject's exercise capacity and to prescribe the exercise intensity, we suggest to use the aerobic gas exchange threshold to prescribe aerobic exercise in overweight and obese subjects.

\section{REFERENCES}

[1] Alwan, A. (2010) Global status report on non-communicable diseases. World Health Organization.
[2] World Health Organization Western Pacific Region, International Association for the Study of Obesity, International Obesity Task Force (2000) Redefining obesity and its treatment, World Health Organization.

[3] Fujie, S., Iemitsu, M., Murakami, H., Sanada, K., Kawano, H., Gando, Y., et al. (2013) Higher cardiorespiratory fitness attenuates arterial stiffening associated with the Ala54Thr polymorphism in FABP2. Physiological Genomics, 45, 237-242.

doi:10.1152/physiolgenomics.00089.2012

[4] Vanhees, L., De Sutter, J., Gelada, S.N., Doyle, F., Prescott, Cornelissen, E., et al. (2012) EACPR. Importance of characteristics and modalities of physical activity and exercise in defining the benefits to cardiovascular health within the general population: Recommendations from the EACPR (Part I). European Journal of Preventive Cardiology, 19, 670-686. doi: $10.1177 / 2047487312437059$

[5] León-Muñoz, L.M., Martínez-Gómez, D., Balboa-Castillo, T., López-García, E., Guallar-Castillón, P. and Rodríguez-Artalejo, F. (2013) Continued sedentariness, change in sitting time, and mortality in older adults. Medicine \& Science in Sports \& Exercise.

[6] Wannamethee, S.G., Shaper, A.G. and Walker, M. (1998) Changes in physical activity, mortality, and incidence of coronary heart disease in older men. Lancet, 351, 16031608. doi:10.1016/S0140-6736(97)12355-8

[7] Xue, Q.L., Bandeen-Roche, K., Mielenz, T.J., Seplaki, C.L., Szanton, S.L., Thorpe, R.J., et al. (2012) Patterns of 12 -year change in physical activity levels in community-dwelling older women: can modest levels of physical activity help older women live longer? American Journal of Epidemiology, 176, 534-543. doi:10.1093/aje/kws125

[8] Booth, F.W. and Lees, S.J. (2007) Fundamental questions about genes, inactivity, and chronic diseases. Physiological Genomics, 28, 146-157.

[9] Anderson, L.H., Martinson, B.C., Crain, A.L., et al. (2005) Health care charges associated with physical inactivity, overweight, and obesity. Preventing Chronic Disease, 2, A09.

http://www.cdc.gov/pcd/issues/2005/oct/04_0118.htm

[10] Colditz, G.A. (1999) Economic costs of obesity and inactivity. Medicine \& Science in Sports \& Exercise, 31, S663-S667.

[11] World Health Organization (2004) Global strategy on diet, physical activity and health. World Health Organization. http://www.who.int/dietphysicalactivity/strategy/eb11344 len/index.html doi:10.1097/00005768-199911001-00026

[12] Bouchard, C., Blair, S.N. and Haskell, W.L. (2007) Physical activity and health. Human Kinetics, Champaign.

[13] Myers, J., Prakash, M., Froelicher, V., Do, D., Partington, S. and Atwood, J.E. (2002) Exercise capacity and mortality among men referred for exercise testing. The New England Journal of Medicine, 346, 793-801. doi:10.1056/NEJMoa011858

[14] Kodama, S., Saito, K., Tanaka, S., Maki, M., Yachi, Y., Asumi, M., et al. (2009) Cardiorespiratory fitness as a quantitative predictor of all-cause mortality and cardiovascular events in healthy men and women: A meta- 
analysis, JAMA, 301, 2024-2035.

doi:10.1001/jama.2009.681

[15] Blair, S.N., Kohl, H.W. 3rd., Paffenbarger, R.S. Jr., Clark, D.G., Cooper, K.H. and Gibbons, L.W. (1989) Physical fitness and all-cause mortality. A prospective study of healthy men and women. JAMA, 3, 2395-2401. doi:10.1001/jama.1989.03430170057028

[16] Kunitomi, M., Takahashi, K., Wada, J., Suzuki, H., Miyatake, N., Ogawa, S., et al. (2007) Re-evaluation of exercise prescription for Japanese type 2 diabetic patients by ventilatory threshold. Diabetes Research and Clinical Practice, 50, 109-115. doi:10.1016/S0168-8227(00)00170-4

[17] Mollaoglu, H., Ucok, K., Kaplan, A., Genc, A., Mayda, H., Guzel, H.I. et al. (2012) Association analyses of depression, anxiety, and physical fitness parameters in Turkish obese adults. Journal of Back and Musculoskeletal Rehabilitation, 25, 253-260.

[18] Ortiz-Galeano, I., Sánchez-López, M., Notario-Pacheco, B., Miota Ibarra, J., Fuentes Chacón, R. and MartínezVizcaíno, V. (2012) Relationship between weight status, physical fitness levels and blood pressure components in young women. Revista Española de de Salud Pública, 86, 523-531.

[19] Schjerve, I.E., Tyldum, G.A., Tjønna, A.E., Stølen, T., Loennechen, J.P., Hansen, H.E., et al. (2008) Both aerobic endurance and strength training programmes improve cardiovascular health in obese adults. Clinical Science, 115, 283-293. doi:10.1042/CS20070332

[20] Zavorsky, G.S. and Hoffman, S.L. (2008) Pulmonary gas exchange in the morbidly obese. Obesity Reviews, 9, 326-339. doi:10.1111/j.1467-789X.2008.00471.x

[21] de Souza, S.A., Faintuch, J. and Sant'anna, A.F. (2010) Effect of weight loss on aerobic capacity in patients with severe obesity before and after bariatric surgery. Obesity Surgery, 20, 871-875. doi:10.1007/s11695-010-0109-Z

[22] Belli, T., Ackermann, M.A., Ribeiro, L.F., Langeani, R., Galdino da Silva, R. and Baldissera, V. (2006) Lactate and ventilatory thresholds in type 2 diabetic women. Diabetes Research and Clinical Practice, 76, 18-23. doi:10.1016/j.diabres.2006.07.028

[23] Dreher, M. and Kabitz, H.J. (2012) Impact of obesity on exercise performance and pulmonary rehabilitation, Respirology, 17, 899-907. doi:10.1111/j.1440-1843.2012.02151.x

[24] Figard-Fabre, H., Fabre, N., Leonardi, A. and Schena, F. (2011) Efficacy of Nordic walking in obesity management. International Journal of Sports Medicine, 32, 407414. doi:10.1055/s-0030-1268461

[25] Rabec, C., de Lucas Ramos, P. and Veale, D. (2011) Respiratory complications of obesity. Archivos de Bronconeumología, 47, 252-261.

doi:10.1016/j.arbres.2011.01.012

[26] Lafortuna, C.L., Chiavaroli, S., Rastelli, F., et al. (2011) Energy cost and cardiovascular response to upper and lower limb rhythmic exercise with different equipments in normal-weight and severely obese individuals. Journal of Endocrinological Investigation, 34, 131-139.

[27] Ruckstuhl, H., Schlabs, T., Rosales-Velderrain, A. and
Hargens, A.R. (2010) Oxygen consumption during walking and running under fractional weight bearing conditions. Aviation Space \& Environmental Medicine, 81, 550-554. doi:10.3357/ASEM.2693.2010

[28] Heden, T.D., Liu, Y., Kearney, M.L., Park, Y., Dellsperger, K.C., Thomas, T.R. and Kanaley, J.A. (2013) Prior exercise and postprandial incretin responses in lean and obese individual. Medicine \& Science in Sports \& Exercise, 3. doi:10.1249/MSS.0b013e318294b225

[29] Mathunjwa, M.L., Semple, S.J. and du Preez, C. (2013) A 10 -week aerobic exercise program reduces cardiometabolic disease risk in overweight/obese female African university students. Ethnicity \& Disease, 23, 143-148.

[30] Millen, A.M., Norton, G.R., Avidon, I. and Woodiwiss, A.J. (2013) Effects of short-term exercise-training on aortic systolic pressure augmentation in overweight and obese individuals. European Journal of Applied Physiology. doi:10.1007/s00421-013-2610-2

[31] Wilson, P.W., D’Agostino, R.B., Levy, D., Belanger, A.M., Silbershatz, H. and Kannel, W.B. (1998) Prediction of coronary heart disease using risk factor categories. Circulation, 97, 1837-1847. doi:10.1161/01.CIR.97.18.1837

[32] Goldstein, D.J. (1992) Beneficial health effects of modest weight loss. International Journal of Obesity and Related Metabolic Disorders, 16, 397-415.

[33] Van Gaal, L.F., Wauters, M.A. and De Leeuw, I.H. (1997) The beneficial effects of modest weight loss on cardiovascular risk factors. International Journal of Obesity and Related Metabolic Disorders, 21, S5-S9.

[34] Donnelly, J.E., Blair, S.N., Jakicic, J.M., Manore, M.M., Rankin, J.W. and Smith, B.K. (2009) American College of Sports Medicine. American College of Sports Medicine Position Stand. Appropriate physical activity intervention strategies for weight loss and prevention of weight regain for adults. Medicine \& Science in Sports \& Exercise, 41, 459-471. doi:10.1249/MSS.0b013e3181949333

[35] Poehlman, E.T., Melby, C.L. and Goran, M.I. (1991) The impact of exercise and diet restriction on daily energy expenditure. Sports Medicine, 11, 78-101. doi:10.2165/00007256-199111020-00002

[36] Ross, R., Freeman, J.A. and Janssen, I. (2000) Exercise alone is an effective strategy for reducing obesity and related comorbidities. Exercise and Sport Sciences Reviews, 28, 165-170.

[37] Skender, M.L., Goodrick, G.K., Del Junco, D.J., et al. (1996) Comparison of 2-year weight loss trends in behavioral treatments of obesity: Diet, exercise, and combination interventions. Journal of the American Dietetic Association, 96, 342-346. doi:10.1016/S0002-8223(96)00096-X

[38] Ross, R. and Janssen, I. (2001) Physical activity, total and regional obesity: Dose-response considerations. Medicine \& Science in Sports \& Exercise, 33, S521-S527. doi:10.1097/00005768-200106001-00023

[39] Utter, A.C., Nieman, D.C., Shannonhouse, E.M., Butterworth, D.E. and Nieman, C.N. (1998) Influence of diet and/or exercise on body composition and cardiorespiratory fitness in obese women. Journal of the International 
Society of Sports Nutrition, 8, 213-222.

[40] Kraemer, W.J., Volek, J.S., Clark, K.L., Gordon, S.E., Puhl, S.M., Koziris, L.P., et al. (1999) Influence of exercise training on physiological and performance changes with weight loss in men. Medicine \& Science in Sports \& Exercise, 31, 1320-1329. doi:10.1097/00005768-199909000-00014

[41] Lafortuna, C.L., Resnik, M., Galvani, C. and Sartorio, A. (2003) Effects of non-specific vs individualized exercise training protocols on aerobic, anaerobic and strength performance in severely obese subjects during a short-term body mass reduction program. Journal of Endocrinological Investigation, 26, 197-205.

[42] Jakicic, J.M., Clark, K., Coleman, E., Donnelly, J.E., Foreyt, J., Melanson, E., et al. (2001) American college of sports medicine position stand. Appropriate intervention strategies for weight loss and prevention of weight regain for adults. American college of sports medicine. Medicine \& Science in Sports \& Exercise, 33, 2145-2456. doi:10.1249/MSS.0b013e3181949333

[43] Jakicic, J.M., Donnelly, J.E., Pronk, N.P., Jawad, A.F. and Jacobsen, D.J. (1995) Prescription of exercise intensity for the obese patient: The relationship between heart rate, $\mathrm{VO} 2$ and perceived exertion. International Journal of Obesity and Related Metabolic Disorders, 19, 382-387.

[44] Boutcher, S.H. (2010) High-intensity intermittent exercise and fat loss. Journal of Obesity, 2011, 868305. doi:10.1155/2011/868305

[45] Heydari, M., Freund, J. and Boutcher, S.H. (2012) The effect of high-intensity intermittent exercise on body composition of overweight young males. Journal of Obesity, 2012, 480467. doi:10.1155/2012/480467

[46] Coquart, J.B., Tourny-Chollet, C., Lemaître, F., Lemaire, C., Grosbois, J.M. and Garcin, M. (2012) Relevance of the measure of perceived exertion for the rehabilitation of obese patients. Annals of Physical and Rehabilitation Medicine, 55, 623-640. doi:10.1016/j.rehab.2012.07.003

[47] Bernhardt, V., Wood, H.E., Moran, R.B. and Babb, T.G. (2013) Dyspnea on exertion in obese men. Respiratory Physiology \& Neurobiology, 185, 241-248. doi:10.1016/j.resp.2012.10.007

[48] Pinet, B.M., Prud'homme, D., Gallant, C.A. and Boulay, P. (2008) Exercise intensity prescription in obese individuals. Obesity, 16, 2088-2095. doi:10.1038/oby.2008.272

[49] Zavorsky, G.S. and Hoffman, S.L. (2008) Pulmonary gas exchange in the morbidly obese. Obesity Reviews, 9, 326339. doi:10.1111/j.1467-789X.2008.00471.X

[50] Da Silva, S.G., Elsangedy, H.M., Krinski, K., de Campos, W., Buzzachera, C.F., Krause, M.P., et al. (2011) Effect of body mass index on affect at intensities spanning the ventilatory threshold. Perceptual Motor Skills, 113, 575-588. doi:10.2466/06.09.15.PMS.113.5.575-588

[51] Katch, V., Weltman, A., Sady, S. and Freedson, P. (1978) Validity of the relative percent concept for equating training intensity. European Journal of Applied Physiology and Occupational Physiology, 39, 219-227. doi:10.1007/BF00421445

[52] Meyer, T., Gabriel, H.H. and Kindermann, W. (1999) Is determination of exercise intensities as percentages of VO2max or HRmax adequate? Medicine \& Science in Sports \& Exercise, 31, 1342-1345. doi:10.1097/00005768-199909000-00017

[53] Aragão, F., Moreira, M.H., Gabriel, R.E. and Abrantes, C.G. (2013) The upper limit of the cardiorespiratory training zone (40-84\%HRR) is overestimated for postmenopausal women. Journal of Science and Medicine in Sport, 14. doi:10.1016/j.jsams.2012.12.008

[54] De Vries, H.A. (1971) Exercise intensity threshold for improvement of cardiovascular-respiratory function in older men. Geriatrics, 26, 94-101.

[55] Emerenziani, G.P., Guidetti, L., Gallotta, M.C., Franciosi, E., Buzzachera, C.F. and Baldari, C. (2013) Exercise intensity and gender difference of 3 different salsa dancing conditions. International Journal of Sports Medicine, 34, 330-335. doi:10.1055/s-0032-1323722

[56] Hansen, D., Jacobs, N., Bex, S., D'Haene, G., Dendale, P. and Claes, N. (2011) Are fixed-rate step tests medically safe for assessing physical fitness? European Journal of Applied Physiology, 111, 2593-2599. doi:10.1007/s00421-011-1886-3

[57] Gordon, N.F. and Scott, C.B. (1995) Exercise intensity prescription in cardiovascular disease. Theoretical basis for anaerobic threshold determination. Journal of Cardiopulmonary Rehabilitation, 15, 193-196. doi:10.1097/00008483-199505000-00005

[58] Miyatake, N., Nishikawa, H., Morishita, A. and Fujii, M. (2005) Re-evaluation of exercise intensity for overweight Japanese men by ventilatory threshold. Diabetes, Obesity and Metabolism, 7, 762-765. doi:10.1111/j.1463-1326.2005.00498.x

[59] Miyatake, N., Nishikawa, H., Morishita, A., Kunitomi, M., Wada, J., Makino, H., et al. (2003) Evaluation of exercise prescription for hypertensive obese men by ventilatory threshold. Journal of the Chinese Medical Association, 66, 572-578.

[60] Meyer, T., Lucía, A., Earnest, C.P. and Kindermann, W. (2005) A conceptual framework for performance diagnosis and training prescription from submaximal gas exchange parameters-Theory and application. International Journal of Sports Medicine, 26, S38-S48. doi:10.1055/s-2004-830514

[61] Wasserman, K., Whipp, B.J., Koyl, S.N. and Beayer, W.L. (1973) Anaerobic threshold and respiratory gas exchange during exercise. Journal of Applied Physiology, 35, 236243.

[62] Aspenes, S.T., Nilsen, T.I., Skaug, E.A., et al. (2011) Peak oxygen uptake and cardiovascular risk factors in 4631 healthy women and men. Medicine \& Science in Sports \& Exercise, 43, 1465-1473. doi:10.1249/MSS.0b013e31820ca81c

[63] Ainsworth, B.E., Haskell, W.L., Whitt, M.C., Irwin, M.L., Swartz, A.M., Strath, S.J., et al. (2000) Compendium of physical activities: An update of activity codes and MET intensities. Medicine \& Science in Sports \& Exercise, 32, S498-S504. doi:10.1097/00005768-200009001-00009

[64] Ainsworth, B.E., Haskell, W.L., Herrmann, S.D., Meckes, N., Bassett, D.R., Tudor-Locke Jr., C., et al. (2011) Com- 
pendium of Physical Activities: A second update of codes and MET values. Medicine \& Science in Sports \& Exercise, 43, 1575-1581. doi:10.1249/MSS.0b013e31821ece12

[65] Tanaka, H., Monahan, K.D. and Seals, D.R. (2001) Agepredicted maximal heart rate revisited. Journal of the American College of Cardiology, 37, 153-156. doi:10.1016/S0735-1097(00)01054-8

[66] Whaley, M.H., Kaminsky, L.A., Dwyer, G.B., Getchell, L.H. and Norton, J.A. (1992) Predictors of ove-and underachievement of age-predicted maximal heart rate. Medicine \& Science in Sports \& Exercise, 24, 1173-1179. doi:10.1249/00005768-199210000-00017

[67] Xhyheri, B., Manfrini, O., Mazzolini, M., Pizzi, C. and Bugiardini, R. (2012) Heart rate variability today. Progress in Cardiovascular Diseases, 55, 321-331. doi:10.1016/j.pcad.2012.09.001

[68] Wu, S., Deng, F., Liu, Y., et al. (2013) Temperature, traffic-related air pollution, and heart rate variability in a panel of healthy adults. Environmental Research, 120, 8289. doi:10.1016/j.envres.2012.08.008

[69] Borg, G. (1998) Borg's Perceived Exertion and Pain Scales. Human Kinetics, Champaign.

[70] Alberton, C.L., Haberland Antunes, A., Dutra Beilke, D., et al. (2012) Maximal and ventilatory thresholds of oxygen uptake and rate of perceived exertion responses to water aerobic exercises. The Journal of Strength \& Conditioning Research. doi:10.1519/JSC.0b013e3182736e47

[71] Demello, J.J., Cureton, K.J., Boineau, R.E. and Singh, M.M. (1987) Ratings of perceived exertion at the lactate threshold in trained and untrained men and women. Medicine \& Science in Sports \& Exercise, 19, 354-362. doi:10.1249/00005768-198708000-00006

[72] Myers, J., Goldsmith, R.L., Keteyian, S.J., Brawner, C.A., Brazil, D.A., Aldred, H., et al. (2010) The ventilatory anaerobic threshold in heart failure: A multicenter evaluation of reliability. Journal of Cardiac Failure, 16, 76-83. doi:10.1016/j.cardfail.2009.08.009

[73] Pereira, D.A., Vieira, D.S., Samora, G.A., Lopes, F.L., Alencar, M.C., Lage, S.M., et al. (2012) Reproducibility of the determination of anaerobic threshold in patients with heart failure. Arquivos Brasileiros de Cardiologia, 94, 771-778. doi:10.1590/S0066-782X2010005000044

[74] Kindermann, W., Simon, G. and Keul, J. (1979) The significance of the aerobic-anaerobic transition for the determination of work load intensities during endurance training. European Journal of Applied Physiology and Occupational Physiology, 42, 25-34. doi:10.1007/BF00421101

[75] Hagan, R.D. and Smith, M.G. (1984) Pulmonary ventila- tion in relation to oxygen uptake and carbon dioxide production during incremental load work. International Journal of Sports Medicine, 5, 193-197. doi:10.1055/s-2008-1025904

[76] Hollmann, W. (2001) 42 years ago-Development of the concepts of ventilatory and lactate threshold. Sports $\mathrm{Me}$ dicine, 31, 315-320. doi:10.2165/00007256-200131050-00002

[77] Aoike, D.T., Baria, F., Rocha, M.L., Kamimura, M.A., Mello, M.T., Tufik, S., et al. (2012) Impact of training at ventilatory threshold on cardiopulmonary and functional capacity in overweight patients with chronic kidney disease. Jornal Brasileiro de Nefrologia, 34, 139-147. doi:10.1590/S0101-28002012000200006

[78] Wasserman, K. (1987) Determinants and detection of anaerobic threshold and consequences of exercise above it. Circulation, 76, 29-39.

[79] Beaver, W.L., Wasserman, K. and Whipp, B.J. (1986) A new method for detecting anaerobic threshold by gas exchange. Journal of Applied Physiology, 60, 2020-2027.

[80] Baldari, C. and Guidetti, L. (2001) $\mathrm{VO}_{2 \max }$, ventilatory and anaerobic thresholds in rhythmic gymnasts and young female dancers. The Journal of Sports Medicine and Physical Fitness, 41, 177-182.

[81] Guidetti, L., Musulin, A. and Baldari, C. (2002) Physiological factors in middleweight boxing performance. The Journal of Sports Medicine and Physical Fitness, 42, 309-314.

[82] Onorati, P., Martolini, D., Ora, J., Valli, G., Fedeli, A. and Palange, P. (2008) Estimation of the exercise ventilatory compensation point by the analysis of the relationship between minute ventilation and heart rate. European Journal of Applied Physiology, 104, 87-94. doi:10.1007/s00421-008-0777-8

[83] Urhausen, A., Coen, B., Weiler, B. and Kindermann, W. (1993) Individual anaerobic threshold and maximum lactate steady state. International Journal of Sports Medicine, 14, 134-139. doi:10.1055/s-2007-1021157

[84] Karapetian, G.K., Engels, H.J. and Gretebeck, R.J. (2008) Use of heart rate variability to estimate LT and VT. International Journal of Sports Medicine, 29, 652-657. doi:10.1055/s-2007-989423

[85] Ahmaidi, S., Hardy, J.M., Varray, A., Collomp, K., Mercier, J. and Préfaut C. (1993) Respiratory gas exchange indices used to detect the blood lactate accumulation threshold during an incremental exercise test in young athletes. European Journal of Applied Physiology and Occupational Physiology, 66, 31-36. doi:10.1007/BF00863396 